\title{
A personalidade jurídica internacional da Santa Sé: status quo
}

\author{
The International Juridical Personality of the Holy See: \\ status quo
}

\section{Sueli Almeida de Oliveira ${ }^{1}$ Allan Victor de Almeida Marandola ${ }^{2}$}

Resumo: Embora a subjetividade internacional da Santa Sé seja efetivamente reconhecida, sua compreensão passa por fundamentação jurídica, sociológica e teológica. É preciso considerá-la não apenas externamente, mas internamente, enquanto realidade distinta da Igreja $\mathrm{Ca}$ tólica e do Estado da Cidade do Vaticano. $\mathrm{O}$ objetivo deste trabalho é examinar as características da subjetividade internacional da Santa Sé, delimitando o conceito de Sé Apostólica com relação à Igreja e ao Vaticano e identificando as características que um sujeito deve possuir para ter reconhecida sua subjetividade internacional. Fizeram-se levantamentos bibliográficos em busca de estudos sobre o tema, além da leitura e cata-

\begin{abstract}
Although the international juridical personality of the Holy See is effectively recognized, its understanding involves juridical, sociological and theological foundations. It must be considered not only externally, but internally, as a distinct reality from the Catholic Church and the Vatican State. The purpose of this paper is to examine the characteristics of the international personality of the Holy See, defining the concept of the Apostolic See in relation to the Church and the Vatican and identifying the characteristics that a subject must possess in order to have its international personality recognized. Bibliographic surveys have been carried out in search of studies on the topic, in addi-
\end{abstract}

1 Mestre em Direito Canônico pela Pontifícia Universidade Gregoriana (2012). Graduada em Direito, com especialização em Direito Civil, Processo Civil e Filosofia do Direito. Doutoranda em Direito Canônico pela Universidade Católica Argentina (UCA). Atualmente, é Presidente da Sociedade Brasileira de Canonistas (SBC), professora do Pontifício Instituto Superior de Direito Canônico e da Pontifícia Universidade Católica do Paraná (PUCPR) e juíza do Tribunal Eclesiástico Interdiocesano de Londrina. Possui conhecimento em Direito Canônico, Direito Processual Civil, Direito Romano e Filosofia do Direito.

2 Graduando do Curso de Teologia da Pontifícia Universidade Católica do Paraná (PUCPR). Possui Licenciatura em Filosofia pela mesma Universidade, ano de 2015. 
logação de diversas obras, pautados no confronto entre o conceito de subjetividade internacional e as peculiaridades da Santa Sé, revelando de que modo aquele conceito se aplica a esta. Considerando que a Igreja foi divinamente instituída por seu Fundador, Jesus Cristo, demonstrou-se que ambos formam uma única pessoa moral. Verificou-se ainda que o Estado do Vaticano é um instrumento que visa garantir à Igreja condições de cumprir com sua missão espiritual, sem temer a hostilidade das nações. Por fim, constatou-se que a Santa Sé, sendo o órgão máximo de governo tanto da Igreja quanto do Vaticano, possui verdadeira subjetividade internacional equiparada a um Estado.

Palavras-chave: Santa Sé. Personalidade jurídica de direito positivo internacional público. Estado da Cidade do Vaticano. Igreja Católica Apostólica Romana.

\section{Introdução}

A Igreja Católica Apostólica Romana (doravante chamada simplesmente de Igreja ou Igreja Católica) possui estatuto ontológico e estrutura complexos. Estruturalmente, quando se considera a Igreja universal, podem-se distinguir a Igreja em si mesma, a Santa Sé ou Sé Apostólica e o Estado da Cidade do Vaticano (doravante chamado simplesmente de Vaticano ou Estado do Vaticano), todos os três governados por sua cabeça visível, o Papa.

Com efeito, neste trabalho, o leitor terá a oportunidade de percorrer o seguinte percurso: na seção 2, tratar-se-á da Igreja em si mesma, examinando os conceitos de Povo de Deus e de Sociedade Juridicamente Perfeita que se lhe costumam atribuir. Constatar-se-á, já nesta seção, se a Igreja possui algum tipo de personalidade. 
Todavia, a diferenciação entre Santa Sé e Estado da Cidade do Vaticano parece não estar bem estabelecida, pois alguns estudiosos do direito internacional atribuem à Santa Sé, em sentido próprio, as características de um Estado, como território e população.

Deste modo, faz-se necessário estabelecer com clareza a distinção entre Santa Sé e Vaticano. A seção 3 versará sobre o Vaticano, desde sua fundação aos elementos conformadores de um Estado, desde seu regime político à sua relação com a comunidade internacional.

Por fim, devem-se considerar os elementos constitutivos da Santa Sé enquanto órgão máximo de chefia da Igreja. De fato, tal condição, que nasce da própria natureza da Santa Sé, determina algumas possibilidades de sua pessoa jurídica, como a causa determina o efeito.

Assim, na seção 4, verificar-se-á se a Santa Sé possui os elementos clássicos de um Estado, e de que modo os possui, e se ela é capaz dos direitos e deveres exercidos pelas pessoas jurídicas no âmbito internacional.

Isso permitirá avaliar se a Sé Apostólica possui, no direito das gentes, personalidade jurídica, e, caso possua, se esta personalidade é estatal ou não-estatal equiparada a um Estado, ou seja, se esta qualidade estatal predica-se da Santa Sé de modo próprio ou análogo.

Consequentemente, este trabalho pretende debruçar-se não sobre as razões históricas, mas sobre as razões jurídicas para afirmar-se ou negar-se à Santa Sé uma personalidade jurídica internacional.

\section{A Igreja}

O Concílio Vaticano II inicia sua constituição dogmática Lumen Gentium (LG 1) ${ }^{3}$, sobre a Igreja Católica Apostólica Romana, definindo-a como sacramento de união dos homens entre si e de sua união com Deus. "Sacramento", aqui, deve ser entendido em sentido lato",

3 Lê-se: Lumen Gentium, n. 1. Para a maior comodidade do leitor, os documentos da Igreja, as Sagradas Escrituras e as obras clássicas da teologia serão citadas segundo o costume da literatura teológica. As edições utilizadas encontram-se nas referências.

4 Em sentido estrito, um sacramento pode ser definido como sinal que realiza aquilo que significa, sendo esta realidade significada algo de sobrenatural, a saber: a 
isto é, como sinal eficaz e instrumento de união. Quem unifica ou realiza tal união é o próprio Espírito Santo. Santificada continuamente pelo Espírito, a Igreja é o caminho de acesso ao Pai, por Cristo.

\subsection{O Povo de Deus: uma pessoa moral}

Ao anunciar que o Reino de Deus estava próximo (Mc 1,15), Jesus deu início à Igreja (LG 5). Deveras, Ele manifestou tal Reino por sua presença, palavras e obras. Aqueles que acolheram sua palavra com fé, passaram a congregar seu rebanho. Este é o germe da Igreja. Desse modo, a Igreja é o Reino de Cristo já presente em mistério (LG 3).

Deus quis salvar os homens não apenas individualmente, mas constituindo-os como povo (LG 9). Primeiramente, a nação israelita foi constituída como seu povo, na Antiga Aliança. Gradualmente, Deus foi manifestando seus desígnios na história e santificando o povo para Si. Todavia, o povo de Israel não era um fim em si mesmo, mas por meio dele Deus prefigurava e preparava a Nova e Eterna Aliança (Jr 31,31-34) em Cristo, perfeita e irrevogável. Trata-se da Igreja (Mt $16,18)$, instituída por Cristo em seu sangue (1Cor 11,25), para congregar judeus e gentios em um só povo, o Novo Povo de Deus, "uma raça eleita, um sacerdócio real, uma nação santa, o povo de sua particular propriedade, [...] vós que outrora não éreis povo, mas agora sois o Povo de Deus" (1Pd 2,9a.10a).

Este povo tem Cristo por cabeça e o Reino de Deus por fim. Por isso, este Reino - que, como se disse, faz-se presente na Igreja - ainda não está consumado, não abrangendo de fato a totalidade dos homens. Entretanto, ele é o mais firme germe de unidade, esperança e salvação para a humanidade. Unidos entre si e com sua cabeça invisível, que é Cristo, os membros deste povo formam um só corpo místico (1Cor 12,13). O Código de Direito Canônico (CIC) recolhe esta doutrina dizendo: "Fiéis são os que, incorporados a Cristo pelo batismo, foram constituídos como povo de Deus e assim, feitos participantes, a seu modo, do múnus sacerdotal, profético e régio de Cristo" (c. $204 \S 1$ ).

graça e/ou o caráter comunicado(s) no sacramento. Neste sentido, a Igreja Católica reconhece sete sacramentos. 
Dessa forma, cabeça e corpo formam uma única pessoa moral. No dizer do Papa São Gregório Magno: "Nosso Redentor mostrou-se como uma só pessoa com a santa Igreja, que ele assumiu" (apud CATECISMO, 1993, n. 795). E Santo Tomás de Aquino: "cabeça e membros são como uma única pessoa mística. Portanto, a satisfação de Cristo pertence a todos os fiéis como a membros seus" (S. Th., IIIa pars, q. 48, a. 2, ad 1).

Destarte, a Igreja é uma pessoa moral pela própria ordenação divina (c. $113 \S 1$; MARTÍN, 1998, p. 252). Na linha do comentário que o Padre Hortal (2015a, p. 76) faz a este cânon, poder-se-ia distinguir a pessoa moral da pessoa jurídica dizendo que aquela deriva da própria natureza do sujeito, enquanto essa é de direito positivo, puramente formal, instituída pela autoridade competente ou reconhecida pelas demais pessoas, como no caso da personalidade jurídica internacional pública estatal. Nada impede, porém, que uma pessoa moral adquira personalidade jurídica, por concessão da autoridade competente ou reconhecimento por parte das demais pessoas.

Segundo Lo Castro (2002, v. 1, p. 773-774), tal distinção entre pessoa moral e pessoa jurídica não tem precedentes, nem no ordenamento canônico, nem em ordenamentos civis. Inclusive, o Código PioBeneditino, de 1917, não diferenciava tais conceitos, utilizando-os indistintamente. A questão foi discutida na Pontifícia Comissão para a Revisão do Código de Direito Canônico, na qual se sugeriu, a certa altura, que não se afirmasse no novo código a personalidade da Igreja, que deveria ser pressuposta, por ser anterior ao direito positivo. Todavia, o legislador fez outra opção, afirmando a personalidade moral da Igreja e distinguindo-a da personalidade jurídica.

Assim como a personalidade física, a personalidade moral é naturalmente ou intencionalmente anterior à personalidade jurídica, sendo-lhe pressuposta (LO CASTRO, 2002, v. 1, p. 773-774). Neste sentido, mesmo um Estado, antes de ser uma pessoa jurídica, é uma pessoa moral. De fato, ele não poderia conferir para si a qualidade de pessoa jurídica, visto que o ato mesmo de concessão pressupõe tal qualidade. Já sua personalidade jurídica exterior (internacional) é reconhecida pelos demais sujeitos internacionais. Dessa maneira, ao reivindicar para si a personalidade moral, a Igreja não abre mão de sua perso- 
nalidade jurídica, mas antes se previne contra atitudes hostis de sociedades seculares, que poderiam alegar que a personalidade da Igreja é meramente de direito positivo, uma ficção jurídica sine fundamentum in re.

\subsection{Sociedade juridicamente perfeita}

Como se disse, a Igreja é sacramento de união entre os homens que, por isso mesmo, formam uma sociedade visível (c. $204 \S 2$ e c. 205). Não obstante, diferentemente da sociedade temporal, a sociedade dos homens congregados na Igreja é espiritual e sobrenatural (LG 8), o que se denota pelo seu fim e pelos meios com que foi dotada para atingi-lo: seu fim é a salvação das almas; já seus meios são numerosos. Poder-se-iam citar, sem a pretensão de ser exaustivos, a celebração litúrgica, a dispensação dos sacramentos, o depósito da fé, compreendida na Palavra de Deus oral (Tradição) e escrita (Bíblia) e guardada pelo Magistério (o Sumo Pontífice e os bispos em comunhão com ele), a disciplina da Igreja (leis canônicas e litúrgicas) etc.

Conforme o ensinamento dos Papas Leão XIII (1885) e Pio XI (1929), nas Encíclicas Immortale Dei (ID) e Divini Illius Magistri (DIM), respectivamente, a Igreja é uma sociedade juridicamente perfeita. Tal conceito, entretanto, não se reduz a uma categoria sociológica, mas é transversal, passando pelas ciências da sociologia, do direito e da metafísica. Fundamentado em princípios destas três ciências, o magistério ordinário e universal da Igreja ensina que uma sociedade é dita perfeita quando contém em si todos os meios necessários para atingir o seu fim próprio. Neste sentido, o Estado é uma sociedade perfeita (DIM 1, a), porque é dotado dos meios para atingir o bem comum temporal, ainda que este ou aquele Estado tenha diversas vicissitudes. Por sua vez, a Igreja foi enriquecida por seu Divino Fundador com todos os meios necessários para a salvação das almas: uma organização autônoma, uma hierarquia própria e verdadeiro poder de regime, também chamado de poder de jurisdição ${ }^{5}$ (c. $129 \S 1$ ), que é o

5 Na esfera civil, a expressão "poder de jurisdição" acabou ficando reservada ao poder judiciário. O exercício de jurisdição, no direito estatal, é o exercício do poder judiciário por parte do magistrado. 
poder de governar o Povo de Deus e que se desdobra nas funções executiva ou administrativa, legislativa e judiciária, sendo independente do Estado, embora em harmonia e cooperação com ele ${ }^{6}$.

Fazendo-se uma leitura conjugada dos cc. 331, 336 e 361 do CIC, constata-se que, na Igreja, exercem poder supremo e pleno o Sumo Pontífice, a Sé Apostólica, sobre a qual se falará abaixo, e o Colégio dos Bispos, sempre em comunhão entre si e com sua cabeça, que é o Papa, e nunca sem ela.

Note-se ainda que, quando se fala de sociedade "perfeita", o conceito de perfeição é estritamente metafísico. O Papa Leão XIII fala de uma "sociedade juridicamente perfeita no seu gênero" (ID 16), enquanto o Papa Pio XI fala de uma sociedade "suprema na sua ordem" (DIM 1, a). Ser perfeito, portanto, é ser a realização máxima ou suprema de uma ordem ou gênero. É o conceito usado na quarta via, das Cinco Vias de Santo Tomás de Aquino: "o que se encontra no mais alto grau em determinado gênero é causa de tudo que é desse gênero" (S. Th., Ia pars, q. 2, a. 3). Se a Igreja precisasse buscar externamente os meios necessários para atingir seu fim, então aquele de quem ela os buscasse - o Estado, por exemplo - seria, neste aspecto, mais perfeito do que ela.

Sendo o fim a que a Igreja tende superior a qualquer fim temporal, ela não pode estar sujeita a qualquer poder civil. De fato, o gênero humano está sujeito a dois poderes: o eclesiástico, relativo às coisas espirituais, e o civil, relativo às coisas temporais. Cada um é soberano em sua esfera, com natureza, meios e fins próprios. Contudo, como ambos os poderes têm o mesmo súdito, a saber, o gênero humano, às vezes uma mesma questão pode estar sujeita ao juízo da Igreja e do Estado, embora cada um em sua esfera (ID 19). O aborto, por exemplo, é considerado pelas leis divina, natural, canônica e civil. É por isso que, como foi dito, o poder espiritual e o poder temporal, apesar de independentes e autônomos, devem, contudo, colaborar harmoniosamente.

6 O CIC, por exemplo, algumas vezes remete à lei civil, conferindo-lhe os mesmos efeitos que possuem as leis eclesiásticas, a teor do c. 22 , exceto se contrariarem o direito divino ou o direito canônico. 
Além disso, como demonstra o Padre Luis Lituma (1940), a soberania da Igreja não apenas pode ser fundamentada teoricamente, como existe de fato. A sociedade composta por mais de 1 bilhão de católicos ao redor do mundo reconhece tal soberania e sujeita-se às suas leis. Desse modo, mesmo os teóricos que veem na vontade popular a fonte da soberania, deveriam insofismavelmente reconhecer a soberania da Igreja. Se a soberania for um direito histórico, então se deve dizer que a Igreja Católica é a pessoa mais antiga em atividade, com séculos de antiguidade em relação aos Estados modernos. A soberania da Igreja foi reconhecida por imperadores, reis e chefes de Estado, tais como Constantino, Teodósio, Justiniano, Pepino o Breve, Carlos Magno, Mussolini et al.

À guisa de conclusão desta seção, deve-se dizer que a Igreja é a congregação de fiéis que professam a mesma fé, reconhecem os mesmos sacramentos e seguem uma determinada disciplina (FORNÉS, 2002, v. 2, t. 1, p. 41-42). Incorporados a Cristo Cabeça, tais fiéis formam o Povo de Deus. Enquanto tal, a Igreja tem fim e meios próprios, e está organizada como sociedade visível, com estrutura, hierarquia e leis próprias, dotada por sua natureza mesma de personalidade moral, e reconhecida internacionalmente como pessoa jurídica soberana.

\section{Vaticano}

No dia 11 de fevereiro de 1929, foram assinados entre a Sé Apostólica e a Itália os Pactos de Latrão, no Palácio de Latrão, em Roma. Os plenipotenciários foram: da parte da Santa $\mathrm{Sé}^{7}$, o Cardeal Pietro Gasparri, Secretário de Estado, e, da parte da Itália, Benito Mussolini, Primeiro-Ministro (TRATTATO, 1929, Premesso, p. 1).

Os Pactos de Latrão compreendem três documentos: o Tratado de Latrão (um tratado político), a Concordata de Latrão e a Convenção Financeira de Latrão. Para o que se propõe neste trabalho, id est, des-

O Estado da Cidade do Vaticano não existia antes de Latrão, não podendo ser parte em um acordo internacional, muito menos no acordo de sua criação. Logo, assinou como parte a Sé Apostólica (SOUZA, 2005, p. 305-306), sobre cuja subjetividade internacional tratar-se-á abaixo. 
fazer a confusão entre Vaticano, Santa Sé e Igreja, para depois poder verificar se a Santa Sé possui personalidade jurídica internacional, basta que se examinem o Tratado de Latrão e algumas leis do Estado da Cidade do Vaticano. Portanto, a Concordata de Latrão e a Convenção Financeira de Latrão não serão contempladas.

\subsection{O tratado de Latrão: território, população e soberania}

O principal objetivo dos Pactos de Latrão era a conciliação entre a Santa Sé e a Itália, o que exigia o reconhecimento da independência e da soberania do Estado da Cidade do Vaticano, o restabelecimento das relações diplomáticas e o reconhecimento dos efeitos civis do matrimônio religioso (SOUZA, 2005, p. 304).

\subsubsection{Território e população}

O Tratado de Latrão criou o Estado da Cidade do Vaticano e delimitou seu território. A planta que delimita suas fronteiras encontra-se no Anexo 1 (Allegato $1^{\circ}$ ) do Tratado, sendo parte integrante do mesmo, a teor do art. 3 (TRATTATO, 1929, p. 1).

A população do Estado do Vaticano é composta por cidadãos e residentes, conforme a lei n. 231, de 22 de fevereiro de 2011, sobre a cidadania, a residência e o acesso (STATO DELLA CITTÀ DEL VATICANO, 2011). Esta lei está de acordo com os arts. 9 a 21 do Tratado de Latrão. A concessão da cidadania está prescrita para algumas pessoas em virtude de sua dignidade, cargo ou ofício, a teor dos arts. 1 a 5 da referida lei. Por sua vez, conforme os arts. 6 a 8 da mesma lei, residente é todo aquele que habita no Vaticano de modo permanente ou temporário, estando sujeito a sua soberania. Assim, é possível que haja cidadãos residentes e não residentes, e é possível que os residentes sejam ou não cidadãos. Por exemplo: o Núncio Apostólico do Brasil é um cidadão não residente, e um funcionário doméstico de um cidadão residente no Vaticano pode receber autorização para residir ali, sem, contudo, ser necessariamente cidadão.

Segundo dados divulgados em 2018 no site oficial do Estado da Cidade do Vaticano, e atualizados a 1 de fevereiro de 2019, o Vatica- 
no possui 618 cidadãos e 453 residentes, sendo: 246 cidadãos residentes, 372 cidadãos não residentes e 207 residentes não cidadãos (STATO DELLA CITTÀ DEL VATICANO, 2018a). Dessa forma, sua população total soma 825 pessoas.

\subsubsection{Soberania}

Acima foi dito que a suprema autoridade da Igreja tem como sujeitos o Sumo Pontífice, a Santa Sé e o Colégio dos Bispos, sempre em comunhão com o Papa e nunca sem ele. Ora, o mesmo não pode ser dito sobre a suprema autoridade do Vaticano, cujos destinatários são o Santo Padre e a Santa Sé, mas não o Colégio dos Bispos. De fato, o Vaticano é um Estado e não se confunde com a Igreja. O Colégio dos Bispos, de instituição divina (LG 22), é uma realidade eclesial, que por si mesma não detém poder de regime em nenhum Estado. Desse modo, o Vaticano é uma pessoa jurídica de direito positivo internacional público estatal que tem como soberano o Papa e a Santa Sé (TRATTATO, 1929, arts. 3, 4 e 26, passim).

Na Encíclica Immortale Dei, o Papa Leão XIII diz que a autoridade sobre um principado civil é uma maneira de salvaguardar a independência da Igreja (ID 18), em vista da realização de sua missão evangélica, uma garantia política contra a hostilidade secular, o que é repetido no Prólogo (Premesso) e no art. 26 do Tratado de Latrão (1929, passim). Dessa maneira, a soberania do Estado do Vaticano é um instrumento que visa garantir de fato e de direito a autonomia política absoluta da Santa Sé no âmbito interno e sua independência política absoluta no âmbito externo.

Para salvaguardar tal autonomia e independência com relação à Itália, sua única fronteira ${ }^{8}$, e assim asseverar que o Vaticano goze das mesmas prerrogativas que os demais Estados soberanos, o Tratado garante-lhe a faculdade e o direito de ter acreditados junto a si representantes de outros Estados, mesmo que estes estivessem em guerra contra a Itália (SOUZA, 2005, p. 304). Trata-se do direito de legação, e é

8 Em geopolítica, o nome que se dá para essa situação é "enclave" (DELLAGNEZZE, 2015, p. 1): quando um território (no caso, o Vaticano) encontra-se dentro dos limites de outro território (no caso, a Itália). 
o que se depreende a partir de uma leitura conjugada dos arts. 12 e 19 do Tratado de Latrão (1929, passim).

A Itália também garantiu, em seu território, livre trânsito de mercadorias estrangeiras destinadas ao Vaticano ou à Santa Sé, com total isenção de impostos e direitos de alfândega (TRATTATO, 1929, art. 20, p. 6).

Além disso, por meio do art. 8 (TRATTATO, 1929, p. 3), a Itália reconhece ao Sumo Pontífice a inviolabilidade devida aos Chefes de Estado, e estabelece que as ofensas e injúrias, os atentados ou a provocação de atentado contra a sua pessoa, em território italiano, serão punidos como se fossem cometidos contra o Chefe de Estado italiano.

Entre 1929, data de assinatura dos Pactos de Latrão, e 1957, os documentos internacionais eram subscritos tanto em nome da Santa Sé quanto em nome do Estado da Cidade do Vaticano. Isso gerava certa confusão e insegurança, pois poderiam levantar-se dúvidas sobre se documentos subscritos pela Santa Sé também o eram em nome do Vaticano, uma vez que este também subscrevia outros documentos em seu próprio nome. Assim, conforme o Padre Salmo Caetano de Souza (2005, p. 292), em 1957, por meio de um comunicado da Secretaria de Estado de Sua Santidade (ou Secretaria de Estado da Santa Sé) ao Secretário Geral das Nações Unidas, a Santa Sé assumia manifestamente e de modo exclusivo a representação da Igreja Católica e do Estado da Cidade do Vaticano.

Em sua atual Constituição da República, a Itália reafirma, em seu art. 7, que "O Estado e a Igreja Católica são, cada um na própria esfera, independentes e soberanos" (ITÁLIA, 2018, p. 7), e que ainda são os Pactos de Latrão que regem as relações entre ambos ${ }^{9}$. Estes Acordos garantem, por exemplo, que, na Itália, terão plena eficácia jurídica e efeitos civis as sentenças ou disposições emanadas da autoridade eclesiástica e oficialmente comunicadas às autoridades italianas, referentes a pessoas eclesiásticas ou religiosas em assuntos de natureza espiritual ou disciplinar (TRATTATO, 1929, art. 23, p. 7). Qualquer mudança nos Acordos deve ser concordada por ambas as partes.

9 Entretanto, a Concordata de Latrão sofreu alterações pelo Acordo Bilateral de 1984, Accordo tra la Santa Sede e la Repubblica Italiana che Apporta Modificazioni al Concordato Lateranense, cujo link foi disponibilizado nas referências. 


\subsection{Regime político}

Os Pactos de Latrão foram ratificados no dia 7 de junho de 1929. Nesta mesma data, o Papa Pio XI promulgou as leis orgânicas do novo Estado, que versavam sobre seus órgãos constitucionais, as fontes do Direito, a cidadania e a residência vaticanas, a segurança pública e o ordenamento administrativo e econômico (MARTÍN, 1998, p. 259).

Quanto a sua forma de governo, o Estado da Cidade do Vaticano é uma monarquia absolutista (STATO DELLA CITTÀ DEL VATICANO, 2018b). De acordo com sua Lei Fundamental, de 26 de novembro de 2000, (AAS 92 [2000], Suppl., p. 75-8010), e a lei n. 274, de 25 de novembro de 2018, sobre o governo do Estado da Cidade do Vaticano (STATO DELLA CITTÀ DEL VATICANO, 2018c), o Papa é o soberano e detém a plenitude dos poderes legislativo, executivo e judiciário. Exerce também o poder legislativo, em seu nome, a Pontifícia Comissão para o Estado da Cidade do Vaticano, composta de um Cardeal Presidente e outros cardeais, nomeados pelo Romano Pontífice por um quinquênio. Esta Comissão emite instruções e promulga regulamentos, todos publicados em um suplemento da Acta Apostolicae Sedis, que é o Boletim Oficial da Santa Sé, chamado de Supplemento per le Leggi e Disposizioni dello Stato della Citta del Vaticano.

O poder executivo é delegado ao Cardeal Presidente da referida Comissão, que assume o título de Presidente do Governo. Nesta função, ele é assistido pelo Secretário Geral e pelo Vice-Secretário Geral. Além disso, é o Presidente que dispõe da organização do governo, composto de Direções e Escritórios Centrais.

$\mathrm{Na}$ elaboração das leis e em outros assuntos, a Comissão e o Presidente do Governo (que é também o Presidente da Comissão, frise-se) contam ainda com o auxílio do Conselheiro Geral e dos Conselheiros do Estado.

De acordo com a lei n. 119, de 21 de novembro de 1987, que aprova o ordenamento judiciário do Estado da Cidade do Vaticano (AAS 79 [1987], Suppl., p. 45-50), e a lei n. 67, de 24 de junho de

10 Lê-se: Acta Apostolica Sedis, ano e volume 92, de 2000, Supplemento, páginas 75 a 80. 
2008 (STATO DELLA CITTÀ DEL VATICANO, 2018d), o poder judiciário tem como órgãos um juiz, um tribunal, uma corte de apelo e uma corte de cassação, cujas atribuições também são exercidas em nome do Papa. Suas competências são regidas pelo Código de Processo Penal e pelo Código de Processo Civil em vigor no Vaticano, bem como pelo Motu Proprio Sulla Giurisdizione degli Organi Giudiziari dello Stato della Città del Vaticano in Materia Penale (FRANCISCO, 2013).

Em seu art. 23, o Tratado de Latrão (TRATTATO, 1929, p. 7) dispõe que as sentenças de tribunais do Estado da Cidade do Vaticano serão executadas, na Itália, conforme as normas do direito internacional.

\subsection{Sua relação com a comunidade internacional dos estados}

Acima foi dito que o Estado da Cidade do Vaticano é uma pessoa jurídica de direito positivo internacional público estatal. Essa afirmação foi sustentada tanto internamente, demonstrando que ele possui elementos próprios de um Estado (território, população, governo próprio e autônomo etc.), quanto externamente, com relação à Itália. Parece oportuno, porém, para confirmar este último ponto, explicitar sua relação com a comunidade internacional dos Estados. Em verdade, o Vaticano é membro de pleno direito desta última e também de organizações intergovernamentais, firmando tratados internacionais e participando de conferências (SOUZA, 2005, p. 311).

De acordo com Carlos García Martín (1998, p. 262), foram ratificados em nome do Vaticano ${ }^{11}$ os seguintes acordos internacionais, dentre outros: Convenção da União de Paris, de 1883, para a proteção da propriedade industrial; Convenção da União de Berna, de 1886, para a proteção das obras artísticas e literárias; Convenção da Organização Mundial da Propriedade Intelectual (OMPI), ratificada pelo Vaticano a 20 de janeiro de 1975; Convenção da União Postal Universal, ratificada pelo Vaticano em 1929; Convenção Postal de Bruxelas, de

11 Sublinhe-se que, desde 1957, a Santa Sé representa exclusivamente o Estado da Cidade do Vaticano, ratificando acordos em seu nome. Antes, porém, dessa data, é possível encontrar acordos ratificados pelo Vaticano em nome próprio. 
1952, ratificada pelo Vaticano a 31 de dezembro de 1953; Convenção da União Internacional de Telecomunicações, ratificada pelo Vaticano em 1932; Convenção Internacional das Telecomunicações, ratificada pelo Vaticano a 21 de março de 1962; Convenção sobre a Circulação Rodoviária, de 1949, a que o Vaticano aderiu a 5 de outubro de 1953; Protocolo relativo à Sinalização Rodoviária, de 1949, a que o Vaticano aderiu a 1 de outubro de 1956; Acordo Europeu Complementar à Convenção sobre a Circulação Rodoviária e ao Protocolo relativo à Sinalização Rodoviária, de 1950, a que o Vaticano aderiu a 1 de outubro de 1956; e Convenção para a Supressão da Falsificação Monetária, a que o Vaticano aderiu a 1 de abril de 1965.

Ainda de acordo com Carlos García Martín (1998, p. 262), o Vaticano é membro, dentre outras, das seguintes organizações internacionais ou intergovernamentais: União Postal Universal, União Internacional de Telecomunicações, Conselho Internacional de Grãos (ou Cereais), Organização Mundial da Propriedade Intelectual, Organização Internacional das Telecomunicações Via Satélite (INTELSAT), Conferência Europeia das Administrações de Correios e Telégrafos (CEPT), Organização Europeia das Telecomunicações por Satélite (EUTELSAT) etc.

A ratificação desses acordos internacionais por parte do Vaticano e sua participação como membro dessas organizações intergovernamentais, "exercendo os mesmos direitos que os outros Estadosmembros, em perfeita paridade com todos eles" (SOUZA, 2005, p. 311), manifestam que esses Estados reconhecem o Vaticano como uma pessoa jurídica de direito positivo internacional público estatal, ou seja, como um Estado de pleno direito.

Desse modo, à luz do direito das gentes e de seu próprio regime interno, é forçoso admitir que o Vaticano possui todos os elementos materiais e formais de um Estado soberano (SOUZA, 2005, p. 309311), tais como território, população, independência externa, governo próprio e autônomo, reconhecimento da parte dos outros Estados, direito de legação ativa e passiva etc. Como foi visto acima, sua finalidade instrumental é servir de base territorial para a Santa Sé (MARTÍN, 1998, p. 261), asseverando-lhe que poderá governar espiritual, 
pastoral e disciplinarmente a Igreja e cumprir com sua missão divina sem ser subjugada por possíveis hostilidades civis.

\section{A Santa Sé: uma pessoa jurídica internacional}

Jesus Cristo conferiu a São Pedro (Mt 16,18-19) e a seus Sucessores o Primado sobre toda a Igreja universal (c. 331), sobre todos os fiéis, inclusive os bispos (c. 333), dando-lhe poder ordinário supremo, pleno, imediato e universal. Este ofício é a Sé Apostólica (LITUMA, 1940, p. 152-153), Sede de Pedro e seus Sucessores.

Conforme os cc. 360 e 361, o termo Santa Sé tem dois sentidos, um estrito e outro lato. Em sentido estrito, como foi dito acima, Santa Sé designa o próprio Romano Pontífice, Sucessor de Pedro, e seu múnus. Em sentido lato, designa o Papa e todos os organismos pelos quais ele exerce este múnus, ou seja, o Papa e a Cúria Romana, composta por diversos dicastérios. Sendo o Papa o titular da Santa Sé, que é constituída "essencialmente pelo Ofício do Romano Pontífice, correspondem a Santa Sé todos os direitos e prerrogativas que competem ao Romano Pontífice" (SOUZA, 2005, p. 290).

Toda a exposição feita acima, sobre a personalidade moral da Igreja, converge agora para a questão da personalidade moral da Santa Sé. De fato, o c. 113 afirma que não apenas a Igreja, mas a própria Sé Apostólica é uma pessoa moral, pois o Papa, o múnus Petrino e os organismos pelos quais ele exerce esse múnus formam uma única pessoa moral. Resta averiguar se a esta pessoa moral é reconhecido algum grau de subjetividade jurídica internacional.

\subsection{A Santa Sé e os elementos que compõem um estado}

Ao contrário do direito estatal público, o direito internacional público não deriva de uma autoridade central superior, mas da coexistência ou do comum acordo das pessoas jurídicas que o compõem. Assim, os sujeitos do direito internacional público não são instituídos por uma autoridade, mas reconhecidos por seus pares (LITUMA, 1940, p. 151). Para isso, o campo dos fatos e dos acontecimentos é basilar. Trata-se do princípio de efetividade, segundo o qual se constata o que efe- 
tivamente existe, extraindo-se, pois, os princípios que regem o direito internacional e suas consequências.

Carlos García Martín (1998, p. 249) esclarece que a justiça e o bem comum são critérios fundamentais do princípio de efetividade. Segundo ele, entidades que cumprem com determinadas características adquirem ipso iure personalidade jurídica internacional. Dessa forma, o reconhecimento por parte dos demais sujeitos diz respeito não apenas à existência ou inexistência de personalidade jurídica, mas ao seu grau de subjetividade.

Fundamentalmente, poder-se-iam dividir os sujeitos internacionais em dois grupos: estatais e não estatais. São estatais aqueles que possuem todos os elementos clássicos que compõem um Estado, a saber: território, população, organização e soberania. Viu-se acima que este é o caso do Vaticano. Por sua vez, são não estatais aqueles que, apesar de não conterem esses elementos em sentido próprio, todavia, contêm alguns em sentido análogo, sendo capazes de exercer os direitos e deveres essenciais de um sujeito internacional (MARTÍN, 1998, p. 249), a saber: o ius legationis, o ius tractatuum, o ius foederum e o direito de participar de conferências internacionais e de ser membro de organizações intergovernamentais.

Que a Santa Sé possua analogamente aqueles elementos, foi demonstrado acima, quando se disse que ela possui verdadeira soberania espiritual e disciplinar, reconhecida no Tratado de Latrão, soberania que, aliás, é a razão de ser do Estado da Cidade do Vaticano. Como se viu, este só existe em função daquela. O Vaticano, Estado soberano em sentido próprio, é um instrumento para salvaguardar a soberania, a autonomia e a independência da Santa Sé.

De igual modo, ao tratar do Vaticano, viu-se que a população de um Estado são aquelas pessoas em relação às quais ele exerce sua soberania. Ora, a soberania da Santa Sé é exercida sobre o conjunto de mais de 1 bilhão de fiéis, que se submetem a sua autoridade espiritual e disciplinar (cc. 331 e 361). Tal é a autoridade que a Santa Sé exerce sobre os católicos que, algumas vezes, eles se indispõem contra a autoridade temporal para manterem-se fiéis à Cátedra de Pedro. O direito público de alguns Estados chega a reconhecer a jurisdição da Igreja 
sobre seus fiéis, no âmbito espiritual ou religioso (LITUMA, 1940, p. 154).

Quanto à organização, a Igreja não apenas recolhe e apresenta o fidei depositum em um conjunto harmonioso de verdades de fé, para o que é fundamental o Magistério Petrino (Lc 22,32) e, portanto, a Santa Sé, como também legisla verdadeiramente sobre a vida e a disciplina dos fiéis, no Direito Canônico e nas leis litúrgicas. Há também a complexa estrutura interna da Cúria Romana, que, em sua organização atual, está estabelecida na Constituição Apostólica Pastor Bonus, do Papa São João Paulo II (1988), tendo sofrido modificações posteriores pelos Papas João Paulo II, Bento XVI e Francisco. A Cúria é composta por organismos ou dicastérios que abrangem a Secretaria de Estado e os Tribunais, Congregações, Comissões, Conselhos etc.

Por fim, apesar de poder subsistir sem um território, como de fato aconteceu durante a Questão Romana (período entre a tomada dos Estados Pontifícios [1870] e a criação do Vaticano [1929]), a Santa Sé também exerce sua soberania sobre um território. Como foi demonstrado, o Estado da Cidade do Vaticano serve de base territorial para a Santa Sé.

3.2 A Santa Sé e os direitos e deveres essenciais de uma pessoa jurídica internacional

Uma vez verificado que a Santa Sé possui, ao menos em sentido análogo, os elementos característicos da pessoa jurídica internacional - ainda que não os possua em sentido próprio, não sendo, pois, um Estado -, resta aferir se ela é capaz de exercer, e se de fato exerce, os direitos e deveres próprios de uma pessoa jurídica internacional.

\subsubsection{Ius legationis}

O direito de legação consiste na capacidade de enviar e receber representantes junto a outras pessoas internacionais. Pode ser ativo ou passivo (MARTÍN, 1998, p. 253): exerce legação ativa o sujeito que envia a outro sujeito internacional uma missão diplomática, e legação 
passiva o sujeito que recebe de outro sujeito internacional uma missão diplomática.

A Santa Sé exerce seu direito de legação ao menos desde o século IV, enviando Legados à Igreja particular de Constantinopla e aos concílios orientais (HORTAL, 2015b, p. 192-193). Desde então, o Papa tem enviado Legados também junto aos governantes temporais, prática que foi plenamente reconhecida e acolhida pelo direito das gentes no Congresso de Viena, em 1815.

De acordo com o Padre Salmo Caetano de Souza (2005, p. 312), ordinariamente, os representantes do Papa no exterior representam-no como Sumo Pontífice, e não como soberano do Vaticano, salvo se lhes for dada delegação especial para representá-lo também deste modo. É o que se depreende da leitura dos cc. 362 a 367 do Código de Direito Canônico: o Romano Pontífice envia seus Legados, Delegados e Observadores às Igrejas particulares, aos Estados, aos conselhos internacionais, conferências e congressos como representantes da Sé Apostólica (c. 363).

De igual modo, o Padre Lituma (1940, p. 156-157) faz notar que os embaixadores acreditados junto ao Romano Pontífice não buscam o soberano do Vaticano, mas o Chefe Supremo da Igreja Católica. Isso se constata pelo fato de que, mesmo durante a Questão Romana (1870-1929), quando carecia de território, a Santa Sé continuou exercendo seu direito de legação ativa e passiva (MARTín, 1998, passim).

Desse modo, vê-se que o Legado Pontifício tem dupla função, ad intra e ad extra, quer dizer, intraeclesial e diplomática. Segundo Martín (1998, p. 251-252) e o Padre Hortal (2015b, p. 193), as categorias de Legados Pontifícios são: Núncio Apostólico, que representa a Santa Sé junto às Igrejas particulares e ao Estado, desempenhando o ofício de embaixador, sendo decano do corpo diplomático do Estado no qual está acreditado; Pró-Núncio, que tem o mesmo grau de representação que o Núncio, mas sem a condição de decano; Internúncio, que representa a Santa Sé como ministro plenipotenciário, em caráter extraordinário, geralmente em países não católicos; Delegado Apostólico, que representa a Santa Sé apenas perante as Igrejas locais, mas não perante o Estado ou a autoridade civil; Delegado, que representa a Santa Sé em um organismo internacional do qual ela é membro ou em 
uma conferência internacional na qual ela tem direito de voto; e Observador, que representa a Santa Sé em um organismo internacional do qual ela não é membro ou em uma conferência internacional na qual ela não tem direito de voto.

De acordo com o Boletim da Sala de Imprensa da Santa Sé, em janeiro de 2017, ela mantinha relações diplomáticas com 182 países, além da União Europeia e da Soberana Ordem Militar de Malta, dos quais 88 mantêm embaixadas com sede em Roma (BOLLETTINO DELLA SALA STAMPA DELLA SANTA SEDE, 2017). Vê-se, portanto, que a Sé Apostólica é capaz de exercer e que de fato exerce o direito de legação ativa e passiva, e que isso é reconhecido no direito internacional.

\subsubsection{Ius tractatuum}

O ius tractatuum é o direito de ser parte em acordos jurídicos criadores de normas internacionais. Tais acordos podem ser bilaterais ou multilaterais, conforme participem dele, respectivamente, duas ou mais pessoas jurídicas internacionais (MARTíN, 1998, passim).

Os acordos posteriores a 1980, firmados entre a Sé Apostólica e outros sujeitos internacionais, regem-se pela Convenção de Viena sobre o Direito dos Tratados, de 23 de maio de 1969, ratificada pela Santa Sé a 22 de fevereiro de 1977.

A Santa Sé tem sido parte de vários acordos internacionais, tais como os Pactos de Latrão ou o Acordo Brasil-Santa Sé (BRASIL, 2010). É praticamente impossível elencar todos os acordos internacionais firmados pela Santa Sé, dado o parco limite de páginas deste trabalho. Entre os anos de 1098 e 1981, por exemplo, a Santa Sé firmou mais de 370 acordos internacionais bilaterais, ou seja, sem contar os multilaterais (MARTÍN, 1998, p. 255).

Destarte, Carlos García Martín cita os seguintes acordos multilaterais: Convenção Relativa ao Estatuto dos Refugiados, de 28 de julho de 1951, ratificada pela Santa Sé a 15 de março de 1956; Convenção sobre a Prestação de Alimentos no Estrangeiro, de 20 de junho de 1956, ratificada pela Santa Sé a 5 de outubro de 1964; Convenção Única sobre os Entorpecentes, de 30 de março de 1961, ratificada pela 
Santa Sé a 1 de setembro de 1970; Protocolo sobre a Convenção Única sobre os Entorpecentes de 1961, ratificada pela Santa Sé a 7 de janeiro de 1976; Convenção de Viena sobre as Relações Diplomáticas, de 18 de abril de 1961, ratificada pela Santa Sé a 17 de abril de 1964; Convenção de Viena sobre Relações Consulares, de 24 de abril de 1963, ratificada pela Santa Sé a 8 de outubro de 1977; Convenção sobre a Eliminação de todas as Formas de Discriminação Racial, de 21 de dezembro de 1965, ratificada pela Santa Sé a 1 de maio de 1969; Convenção Internacional sobre a Eliminação de toda Forma de Discriminação Racial, de 7 de março de 1966, ratificada pela Santa Sé a 1 de maio de 1969; Convenção sobre as Substâncias Psicotrópicas, de 21 de fevereiro de 1971, ratificada pela Santa Sé a 7 de janeiro de 1976; Convenção de Viena sobre a Sucessão de Estados em Matéria de Tratados, de 23 de agosto de 1978, que a Santa Sé firmou sem ratificar.

Como exemplos de acordos bilaterais, podem-se mencionar os seguintes (BOLLETTINO DELLA SALA STAMPA DELLA SANTA SEDE, 2017): em 2016, entraram em vigor os Avenants $^{12}$ de 4 de maio de 1974, de 21 de janeiro de 1999 e de 12 de julho de 2005, relativos à Chiesa e al Convento della Trinità dei Monti, em Roma; em 2016, entrou em vigor o Acordo entre a Santa Sé e o Estado da Palestina; a 15 de outubro de 2016, entrou em vigor a Convenção entre a Santa Sé e a Itália, sobre matéria fiscal, firmada a 1 de abril de 2015; a 3 de março de 2016, ratificou-se a Concordata entre a Santa Sé e a República Democrática de Timor-Leste, sobre a situação jurídica da Igreja neste país; a 20 de maio de 2016, foi firmado um Acordo entre a Santa Sé e a República Democrática do Congo; a 6 de setembro de 2016, foi firmado um Acordo entre a Santa Sé e a República Centro-Africana; a 15 de setembro de 2016, foi selado um Memorando de Entendimento entre a Secretaria Papal e o Governo dos Emirados Árabes Unidos, sobre a isenção mútua de vistos de entrada para titulares de passaportes diplomáticos e de passaportes oficiais e de serviço; a 19 de setembro de 2016, a Santa Sé aderiu, em nome próprio e em nome do Estado da Cidade do Vaticano, à Convenção das Nações Unidas contra a

12 Um avenant é um aditivo contratual por meio do qual as partes modificam uma cláusula do acordo original ou pactuam uma nova cláusula que não estava nele. 
Corrupção, de 31 de outubro de 2003; a 22 de outubro de 2016, foi firmada uma Concordata entre a Santa Sé e a República de Benin, sobre a situação jurídica da Igreja neste país; a 23 de novembro de 2016, entrou em vigor o Avenant às Convenções Diplomáticas de 14 de maio e de 8 de setembro de 1828, firmado entre a Santa Sé e a França, a 25 de julho de 2016.

Dessa forma, é inegável que a Santa Sé tem exercido o direito de celebrar acordos jurídicos bilaterais e multilaterais capazes de gerar direitos e obrigações para as partes signatárias, e que isso é reconhecido pelos demais sujeitos internacionais.

\subsubsection{Ius fœederum}

Trata-se da capacidade de mediar, arbitrar ou exercer bons ofícios em conflitos internacionais, em vista de uma solução pacífica (MARTÍN, 1998, p. 253). Segundo Mariana Ribeiro Santiago (2009), os bons ofícios são a tentativa amistosa de solucionar conflitos internacionais, em que um sujeito não envolvido, sem participar ativamente das negociações, aproxima as partes interessadas para que negociem. Por sua vez, na mediação, o sujeito que serve de mediador envolve-se ativamente nas negociações, propondo soluções, embora sem poder decisório ou vinculante. Por fim, na arbitragem, as partes litigantes elegem um sujeito para arbitrar a solução do conflito, com poder decisório e vinculante, conforme as normas previamente estabelecidas em um compromisso arbitral. Essas normas devem respeitar os acordos internacionais ratificados pelas partes.

Em todos estes casos, a ajuda de um sujeito externo pode ser oferecida ou solicitada, sendo que o oferecimento ou a recusa por ele ou por um dos envolvidos não é considerada um ato hostil.

Novamente, serão elencados alguns exemplos dados por Carlos García Martín (1998, p. 256), sem a pretensão de ser exaustivos. A Santa Sé exerceu bons ofícios: na controvérsia entre Grã-Bretanha e Portugal, sobre as fronteiras do Congo (1890), e na prevenção do conflito entre Estados Unidos e Espanha, em relação a Cuba (1898).

Mediou, dentre outros: a prevenção de uma guerra entre França e Prússia (1870); a petição de Grã-Bretanha e Venezuela, para definir 
as fronteiras da Guiana (1894); e o conflito entre Argentina e Chile, pelo Canal de Beagle (1978).

E atuou como árbitro nos seguintes conflitos: controvérsias entre Espanha e Alemanha, sobre as Ilhas Carolinas (1885); delimitação das fronteiras entre Equador e Peru (1893); delimitação das fronteiras entre Haiti e São Domingos (1895); delimitação das fronteiras entre Argentina e Chile (1900-1903); delimitação das fronteiras entre Equador e Colômbia (1906); e controvérsia entre Brasil e Bolívia, sobre a posse das minas de ouro (1914).

Há ainda um Tratado de 1905 por meio do qual Colômbia e Peru decidiram submeter-se à arbitragem da Santa Sé em todos os conflitos futuros, salvo as exceções previstas. Assim, a Sé Apostólica tem amplamente reconhecido seu ius foederum, ao qual já recorreram, inclusive, superpotências.

\subsubsection{Participação em organismos internacionais}

Por meio de seus dicastérios, a Santa Sé tem participado como membro ou observador de várias conferências e organismos internacionais. A diferença entre um membro e um observador é que o membro possui direitos procedimentais que o observador não possui, sendo substancialmente três (MARTÍN, 1969, p. 287): o direito de voto, o direito de fazer propostas procedimentais e o direito de incluir pautas na ordem do dia.

Devem-se diferenciar ainda as conferências internacionais dos organismos internacionais. A distinção fundamental reside no fato de que estes possuem um secretariado estável que assegura a continuidade de suas atividades, enquanto aquelas possuem uma atuação bem delimitada e localizada no tempo, embora possam gerar efeitos igualmente permanentes, tais como as convenções.

Conforme dados divulgados em seu site oficial (HOLY SEE SECRETARIAT OF STATE, 2001), a Santa Sé é membro de 12 organizações internacionais, entre as quais: Conferência das Nações Unidas sobre Comércio e Desenvolvimento (UNCTAD), Conselho Internacional de Grãos (IGC), Instituto Internacional para a Unificação do Direito Privado (UNIDROIT), Organização Mundial da Proprieda- 
de Intelectual (WIPO) e União Internacional de Telecomunicações (ITU).

Além disso, é observador permanente (não membro) de 15 organizações internacionais, entre as quais: Organização das Nações Unidas (ONU), Organização das Nações Unidas para a Educação, Ciência e a Cultura (UNESCO), Organização Internacional do Trabalho (OIT), Organização Mundial da Saúde (OMS) e Organização Mundial do Comércio (OMC).

Por fim, é observador em base informal de 6 organizações internacionais, entre as quais: Organização Internacional da Aviação Civil (ICAO); Organização Marítima Internacional (IMO) e Organização Meteorológica Mundial (WMO) ${ }^{13}$.

Se, por um lado, a Santa Sé não é formalmente um Estado, por não possuir seus elementos clássicos em sentido próprio, por outro, os organismos internacionais não criaram um estatuto exclusivo para ela, cujo caso é sui generis. Antes, optaram por equipará-la a um Estado. Com efeito, a Convenção de Viena sobre o Direito dos Tratados, de 1969, firmada e ratificada pela Santa Sé, afirma, em seu art. 1, que a Convenção aplica-se aos tratados entre Estados (MARTíN, 1969, p. 269). E os organismos internacionais citados acima, dos quais ela participa, também são compostos por Estados.

Por sua vez, em favor da Sé Apostólica, a Convenção de Viena sobre as Relações dos Estados com os Organismos Internacionais, de 1975, equiparou as missões permanentes de observação dos Estados não membros às missões permanentes de Estados membros, equiparando, consequentemente, o perfil diplomático protocolar dos observadores permanentes ao perfil dos delegados, ainda que mantendo suas diferenças essenciais.

Caso peculiar é o da participação da Santa Sé na ONU. De fato, ela goza do estatuto de observador permanente como Estado não membro $^{14}$. A importância disso fica mais clara quando se salienta que

13 Há também as organizações intergovernamentais regionais das quais a Santa Sé participa, que podem ser encontradas, igualmente, em seu site oficial: $<$ http://www.vatican.va/news_services/press/documentazione/ documents/corpo-diplomatico/corpo-diplomatico_regionali_elenco_en.html>.

14 "Recalling that the Holy See became a Permanent Observer State at the United Nations on 6 April 1964 [...]. Recalling that the Holy See contributes financially 
a ONU admite quatro tipos de observadores permanentes: Estados não membros, organizações intergovernamentais, organizações não governamentais e movimentos de libertação nacional (MARTÍN, 1969, p. 272-274). Em outras palavras, a Santa Sé participa ativamente das atividades da ONU, porém, sem direito a voto. Em todo caso, isso significa que a ONU também a equipara a um Estado, embora não membro (UNITED NATIONS, 2004). Depois dos Estados membros, os Estados não membros são os sujeitos que possuem maior grau de participação, com direito a emitir declarações, propostas (não procedimentais) e réplicas, além de gozar de imunidades (MARTÍN, 1969, p. 272274).

\section{Considerações finais}

Neste trabalho, restou demonstrado que a Igreja, o Vaticano e a Santa Sé, embora sejam realidades que se refiram mutuamente, contudo, não se confundem. A Igreja Católica Apostólica Romana é o Corpo Místico instituído pelo próprio Cristo para $\mathrm{Si}$, formando com Ele uma única pessoa moral. É o Povo de Deus que, professando a mesma fé, os mesmos Sacramentos e a mesma disciplina, está hierarquicamente organizado em uma sociedade visível juridicamente perfeita.

Por sua vez, o Estado da Cidade do Vaticano possui, em sentido próprio, todos os elementos conformadores de um Estado, ou seja, território, população, organização e soberania, sendo reconhecido pelos demais sujeitos internacionais como uma pessoa jurídica estatal. Entretanto, o Vaticano não é um fim em si mesmo, mas existe em função da Igreja, isto é, para que ela possa cumprir com sua missão divina sem temer as possíveis hostilidades dos governos civis. Consequentemente, o Estado do Vaticano serve de base territorial para a Sé Apostólica.

Finalmente, a Santa Sé pode ser tomada em dois sentidos: em sentido estrito, compreende o Santo Padre, o Papa, e seu múnus Petrino. Em sentido lato, compreende também os organismos pelos quais o

to the general administration of the United Nations in accordance with the rate of assessment for the Holy See as a non-member State" (UNITED NATIONS, 2004, p. 9, grifo nosso). 
Papa exerce seu múnus, isto é, a Cúria Romana. A Santa Sé possui analogamente os elementos que compõem um Estado, e exerce verdadeiramente os direitos próprios de um, a saber, o ius legationis, o ius tractatuum, o ius foederum e o direito de participar de conferências internacionais e de ser membro de organizações intergovernamentais, sendo assim uma pessoa jurídica de direito positivo internacional público não estatal, porém equiparada a um Estado.

\section{Bibliografia}

ACCORDO tra la Santa Sede e la Repubblica Italiana che Apporta Modificazioni al Concordato Lateranense. 18 febbr. 1984. Disponível em: <http://www.vatican.va/roman_curia/secretariat_ state/archivio/documents/rc_seg-st_19850603_santa-sede-italia_ it.html>. Acesso em: 26 maio 2019.

BÍBLIA DE JERUSALÉM. Português. São Paulo: Paulus, 2015. 2206 p. (Encadernada).

BOLLETTINO DELLA SALA STAMPA DELLA SANTA SEDE. Nota Informativa sui Rapporti Diplimatici della Santa Sede. Roma, 9 genn. 2017. Disponível em: <http://press.vatican.va/ content/salastampa/it/bollettino/pubblico/2017/01/09/0016/ 00033.html>. Acesso em: 2 jun. 2019.

BRASIL. Decreto $\mathrm{n}^{\mathrm{o}}$ 7.107, de 11 de fevereiro de 2010. Promulga o Acordo entre o Governo da República Federativa do Brasil e a Santa Sé relativo ao Estatuto Jurídico da Igreja Católica no Brasil, firmado na Cidade do Vaticano, em 13 de novembro de 2008. Disponível em: <http://www.planalto.gov.br/ccivil_03/ ato2007-2010/2010/decreto/d7107.htm>. Acesso em: 15 dez. 2019.

CATECISMO da Igreja Católica. 2. ed. Petrópolis: Vozes, 1993.

CÓDIGO DE DIREITO CANÔNICO. 23. ed. São Paulo: Loyola, 2015. 
CONCÍLIO VATICANO II. Constituição Dogmática Lumen Gentium: sobre a Igreja. Roma, 1964. Disponível em: $<$ http://www.vatican.va/archive/hist_councils/ii_vatican_council /documents/vat-ii_const_19641121_lumen-gentium_po.html >. Acesso em: 10 maio 2019.

DELLAGNEZZE, René. Os enclaves, os exclaves e a soberania do Estado no mundo globalizado. Centro de Pesquisas Estratégicas Paulino Soares de Sousa da Universidade Federal de Juiz de Fora, Juiz de Fora, p. 1-130, fev. 2015. Disponível em: $<$ http://www.ecsbdefesa.com.br/defesa/fts/EXMG.pdf $>$. Acesso em: 22 maio 2019.

FORNÉS, Juan. Comentario al c. 205. In: MARZOA, Ángel; MIRAS, Jorge; RODRÍGUEZ-OCAÑA, Rafael (Coords). Comentario Exegético al Código de Derecho Canónico. 3. ed. Pamplona, Espanha: EUNSA, 2002. v. 2, t. 1. p. 40-43.

FRANCISCO, Papa. Motu Proprio Sulla Giurisdizione degli Organi Giudiziari dello Stato della Città del Vaticano in Materia Penale. Roma, 2013. Disponível em: <https://w2.vatican.va/ content/francesco/it/motu_proprio/documents/papa-francescomotu-proprio_20130711_organi-giudiziari.html>. Acesso em: 17 maio 2019.

HOLY SEE SECRETARIAT OF STATE. Bilateral and Multilateral Relations of the Holy See: the Holy See participates in various International Intergovernmental Organizations an Bodies. Roma, 1 feb. 2001. Disponível em: <http://www.vatican.va/news services/press/documentazione/documents/corpo-diplomatico/ corpo-diplomatico_regionali_elenco_en.html $>$. Acesso em: 4 jun. 2019.

HORTAL, Padre Jesús. Comentário ao c. 113. In: CÓDIGO DE DIREITO CANÔNICO. 23. ed. São Paulo: Loyola, 2015a. p. 76.

. Comentário ao c. 362. In: CÓDIGO DE DIREITO CANÔNICO. 23. ed. São Paulo: Loyola, 2015b. p. 192-193. 
ITÁLIA. Constituição (1947). Constituição da República Italiana: Costituzione Italiana: edizione in lingua portoghese: promulgada em 27 de dezembro de 1947. Roma: Senato della Repubblica, 2018. 78 p. Disponível em: <https://www.senato.it/ application/xmanager/projects/leg18/file/repository/relazioni/ libreria/novita/XVII/COST_PORTOGHESE.pdf $>$. Acesso em: 23 maio 2019.

JOÃO PAULO II, Papa. Constituição Apostólica Pastor Bonus: sobre a Cúria Romana. Roma, 1988. Disponível em: <http://w2. vatican.va/content/john-paul-ii/pt/apost_constitutions/ documents/hf_jp-ii_apc_19880628_pastor-bonus.html>. Acesso em: 27 maio 2019.

LEÃO XIII, Papa. Carta Encíclica Immortale Dei: sobre a constituição cristã dos estados. Roma, 1885. Disponível em: $<$ https://w2.vatican.va/content/leo-xiii/pt/encyclicals/documents/ hf_l-xiii_enc_01111885_immortale-dei.html >. Acesso em: 11 maio 2019.

LITUMA, Padre Luis. La soberania de la Iglesia y de la Santa Sede. Revista de la Universidad Católica, Perú, t. 8, n. 2-3, p. 143158, mayo/jun. 1940. Disponível em: <http://repositorio.pucp. edu.pe/index/bitstream/handle/123456789/53339/la\%20soberani a\%20de\%201a\%20iglesia\%20y\%20de \%201a\%20santa\%20sede. pdf? sequence $=1 \&$ is Allowed=y $>$. Acesso em: 13 maio 2019.

LO CASTRO, Gaetano. Comentario al c. 113. In: MARZOA, Ángel; MIRAS, Jorge; RODRÍGUEZ-OCAÑA, Rafael (Coords). Comentario Exegético al Código de Derecho Canónico. 3. ed. Pamplona, Espanha: EUNSA, 2002. v. 1. p. 772-776.

MARTÍN, Carlos García. El estatuto jurídico de la Santa Sede en las naciones unidas. Ius Canonicum, Navarra, Espanha, v. 38, n. 75, p. 247-289, 1998. Disponível em: <http:/dadun.unav.edu/ bitstream/10171/3280/1/75-08.Otros3.C.Garcia.pdf>. Acesso em: 29 abr. 2019. 
PIO XI, Papa. Carta Encíclica Divini Illius Magistri: acerca da educação cristã da juventude. Roma, 1929. Disponível em: $<$ https://w2.vatican.va/content/pius-xi/pt/encyclicals/documents/ hf_p-xi_enc_31121929_divini-illius-magistri.html >. Acesso em: 12 maio 2019.

SANTIAGO, Mariana Ribeiro. Arbitragem Internacional. Revista Jus Navigandi, Teresina, a. 14, n. 2169, 9 jun. 2009. Disponível em: $<$ https://jus.com.br/artigos/12948/arbitragem-internacional $>$. Acesso em: 3 jun. 2019. ISSN: 1518-4862.

SOUZA, Salmo Caetano de. A Santa Sé e o Estado da Cidade do Vaticano: distinção e complementaridade. Revista da Faculdade de Direito da Universidade de São Paulo, São Paulo, v. 100, p. 287314, jan./dez. 2005. Disponível em: $<$ http://www.revistas.usp.br/rfdusp/article/view/67675/70283>. Acesso em: 30 abr. 2019.

STATO DELLA CITTÀ DEL VATICANO. Legge n. 119, 21 nov. 1987. In: APOSTOLICÆ SEDIS. Acta Apostolica Sedis: commentarium officiale, Vaticano, a./v. 79, 1987, Suppl., p. 45-50. Disponível em: <http://www.vatican.va/archive/aas/documents/ AAS-79-1987-ocr.pdf>. Acesso em: 18 maio 2019. . Legge Fondamentale dello Stato della Città del Vaticano, 26 nov. 2000. In: APOSTOLICÆ SEDIS. Acta Apostolica Sedis: commentarium officiale, Vaticano, a./v. 92, 2000, Suppl., p. 7580. Disponível em: <http://www.vatican.va/archive/aas/ documents/AAS-92-2000-ocr.pdf> . Acesso em: 19 maio 2019.

. Legge n. 231, 22 febbr. 2011. Legge sulla cittadinanza, la residenza e l'accesso. Disponível em: <https://www.vaticanstate. $\mathrm{va} /$ it/stato-governo/legislazione-e-normativa/leggi-e-decreti/ category/1-alcune-leggi.html?download=11:legge-sullacittadinanza-la-residenza-e-l-accesso $>$. Acesso em: 25 maio 2019.

. Popolazione. 3 luglio 2018a. Disponível em: <https://www. vaticanstate.va/it/stato-governo/note-generali/popolazione. html>. Acesso em: 24 maio 2019. 
. Organi dello Stato. 3 luglio 2018b. Disponível em: <https:// www.vaticanstate.va/it/stato-governo/organi-stato/organi-dellostato.html>. Acesso em: 14 maio 2019.

. Legge n. 274, 25 nov. 2018c. Legge sul Governo dello Stato della Città del Vaticano. Disponível em: <https://www. vaticanstate.va/phocadownload/leggi-decreti/Legge $\%$ 20CCLXXIV\%20Legge $\% 20$ sul $\% 20$ Governo $\% 20$ dello $\% 20$ Stato $\% 20$ della $\% 20$ Citta $\% 20$ del $\% 20$ Vaticano.pdf $>$. Acesso em: 20 maio 2019.

. Organi del Potere Giudiziario. 3 luglio 2018d. Disponível em: <https://www.vaticanstate.va/it/stato-governo/organi-stato/ organi-potere-giudiziario.html $>$. Acesso em: 16 maio 2019.

TOMÁS DE AQUINO. Suma Teológica. 3. ed. São Paulo: Loyola, 2009a. v. 1.

. Suma Teológica. 2. ed. São Paulo: Loyola, 2009b. v. 8.

TRATTATO fra la Santa Sede e l'Italia. 11 febbr. 1929. Disponível em: <https://www.vaticanstate.va/it/stato-governo/legislazionee-normativa/leggi-e-decreti/category/1-alcuneleggi.html?download=3:trattato-santa-sede-stato-italiano $>$. Acesso em: 21 maio 2019.

UNITED NATIONS. General Assembly. Resolution A/58/314, on 1 July 2004. Participation of the Holy See in the work of the United Nations. Official records: resolutions and decisions adopted by the general assembly during its fifty-eighth session, New York, v. 3, n. 49, 24 dec. 2003/13 set. 2004. p. 9-10. Disponível em: $\quad<$ https://www.un.org/ga/search/view_doc.asp?symbol= A/58/49(vol.III)(Supp)>. Acesso em: 24 abr. 2019. 